\title{
Nutritional Needs and Attitudes Towards Having a Training Table: Insight from Players from a Division 1 Football Team
}

\author{
Katie Brown, $\mathrm{PhD}, \mathrm{RDN}^{1 *}$, Katelyn Imthurn, $\mathrm{RDN}^{2}$, and Samantha Ramsay, $\mathrm{PhD}, \mathrm{RDN}^{3}$ \\ ${ }^{1,3}$ School of Family and Consumer Sciences, University of Idaho \\ ${ }^{2}$ Sports Dietitian Graduate Assistant, Saint Louis University Athletic Department
}

*Corresponding author: Katie Brown, PhD, RDN, Assistant Professor of Nutrition, School of Family and Consumer Sciences, University of Idaho, Tel: (208) 885-7664; Fax: (208) 885-5751; E-mail: katieb@uidaho.edu

Received Date: $09^{\text {th }}$ December 2014

Accepted Date: $03^{\text {rd }}$ January 2015

Published Date: $09^{\text {th }}$ January 2015
Citation: Brown K, Imthurn K, Ramsay S (2015) Nutritional Needs and Attitudes Towards Having a Training Table: Insight form Players from a Division 1 Football Team. Enliven: J Diet Res Nutr 2(1): 001.

Copyright:@2015Dr.KatieBrown.This is an OpenAccess article published and distributed under the terms of the Creative Commons Attribution License, which permits unrestricted use, distribution and reproduction in any medium, provided the original author and source are credited.

\begin{abstract}
Objective

Assess the nutritional needs of, and attitude towards expanding the provision of nutrition services to a division 1 football team who does not have a sports dietitian or a training table.

Methods

A 26-item questionnaire was developed by two sports dietitians and administered to a football team from a small division 1 school. Demographic information, dietary fueling practices, and football players' attitudes towards the provision of additional nutrition services was assessed. Descriptive statistics were used to summarize athlete demographic characteristics, and Chi squared analysis assessed differences in responses based on grade in school, position, and residence.

Results

Seventy-six football players $(90 \%$ response rate) completed the questionnaire. Sixty-nine percent reported trying to change their weight. The majority reported not consuming pre-workout and/or game snacks ( $88 \%$ and $92 \%$, respectively). Eighty percent of athletes reported consuming only water during exercise, and $75 \%$ reported a lack of energy during a workout. Most (93.4\%) believed they would benefit from a training table; however, only $42 \%$ were willing to have funds reallocated from their stipends to finance it. Results from Chi Squared tests revealed no significant differences in the number of athletes willing to use their stipends for a training table based on year in school $(\mathrm{p}=0.957)$, position $(\mathrm{p}=0.54)$, or residence (on campus vs off-campus) $(\mathrm{p}=0.982)$. Most $(97 \%)$ athletes believed proper nutrition would enhance their performance, and $91 \%$ were willing to meet with a dietitian.

\section{Conclusion}

These findings suggest that the football athletes' fueling and hydration strategies are not sufficient to promote optimal performance and that the athletes believe they would benefit from an expanded provision of nutrition services. Further research is needed to determine effectiveness of training tables as well as the feasibility and sustainability in funding to support a sports dietitian nutritionist and/or training table.
\end{abstract}

\section{Introduction}

Proper nutrition is key to optimizing athletic performance [1]. Previous research documented poor dietary choices among collegiate football players such as high intake of fast food [2], low fruit and vegetable intake [2], and inadequate energy intake [3]. Infrequency of eating is common among athletes $[2,3]$ and may promote muscle catabolism, fat synthesis, and overall undesirable changes in body composition [4]. In addition, there is growing concern that college football players in some positions

Enliven Archive | www.enlivenarchive.org may have unhealthy percent body fat and risk for cardiovascular disease [5-7]. A Registered Dietitian Nutritionist (RDN) could guide athletes in appropriate weight gain strategies to minimize risk for disease. Ideally, each collegiate athletic program should have an RDN whose unique training and experience allows him/her to provide nutrition counseling for health and optimal performance, as well as design diets and menus [1]. Registered dietitian nutritionists are equipped to counsel athletes who may have special health/dietary needs such as diabetes or food allergies and intolerances. 
According to the Collegiate and Professional Sports Dietitians Association, fewer than 50 universities in the United States employ a full-time sports dietitian [8]. A survey of athletes and personnel from 100 National College Athletic Association (NCAA) Division I, II, and III institutions revealed that fewer than $60 \%$ of participants reported access to a registered dietitian, and only half reported access to full-time or part-time sports dietitian [9]. Athletes have regular contact with coaches, athletic trainers (AT), and strength and conditioning specialists (SCS) and may be more likely to obtain nutrition information from them. While most ATs and SCSs have some nutrition knowledge [9] they did not demonstrate knowledge in weight management and disordered eating. SCSs and ATs were overconfident and provided in incorrect recommendations. Further, designing diets is outside of the scope of ATs and SCSs [9].

Nutritional counseling may improve athletes' diets [10], and training tables may improve athletes' dietary intake. The training table is usually at a separate venue from other students, and offers a variety of foods to meet the athletes' needs. Ideally a training table utilizes mealtimes as an opportunity for educating athletes on the best food selections for their specific needs. To date, no research has investigated the impact of a training table on athletes' dietary intake or athletic performance. However, creating an environment that supports dissemination of credible nutrition education and provision of healthy meals may enhance athlete health and performance. This study aimed to identify football players' nutritional needs, determine differences in preference for a training table based on year in school, position, etc., and obtain qualitative feedback about their attitudes towards a training table.

\section{Materials and Methods}

In fall of 2013, all 84 football players were asked to complete a questionnaire regarding their nutrition needs and the use of a training table (see Appendix). The University of Idaho Institutional Review Board approved the study. The questionnaire was developed by two sports dietitian nutritionists using previous literature for content validity, and included questions that have previously been used among college football teams $[11,12]$. Football player dietary fueling practices were gathered, their preference for a training table was identified, and demographic questions were included. Free-response questions were presented at the end of the questionnaire to give athletes the opportunity to report their opinion towards the provision of additional nutrition services.

IBM SPSS Statistics (version 21, IBM Corporation, Arnmonk, NY) was used for data analysis. Frequency and descriptive analyses were conducted to summarize athlete demographic characteristics. Chi squared tests, with the use Fisher's Exact test in the case of low expected frequencies, were conducted to determine differences in responses among groups based on grade, position, or residence. Significance was indicated by a p-value $<0.05$.

\section{Results}

\section{Demographic Characteristics of the Athletes}

Seventy-six football players $(90 \%$ response rate $)$ completed the questionnaire, adequately representing each year in school (see Table 1). Average Body Mass Index (BMI) was $29.3 \pm 4.46$. Sixty-nine percent reported trying to change their weight (14\% wanted to lose weight and $55 \%$ wanted to gain weight).
Table 1. Demographics of Football Players from One Small Division 1 School

\begin{tabular}{|c|l|}
\hline \multicolumn{2}{|c|}{$\begin{array}{c}(\mathrm{n}=76) \\
\text { Mean } \pm \text { SD }\end{array}$} \\
\hline Height, ft & $6.10 \pm 0.25$ \\
\hline Weight, lbs & $222 \pm 45$ \\
\hline BMI & $29.3 \pm 4.46$ \\
\hline $\begin{array}{c}\text { Average desired weight } \\
\text { change }\end{array}$ & \pm 8.02 lbs (range $=-30-40)$ \\
\hline & $\mathrm{n}(\%)$ \\
\hline Year in School* & $24(32)$ \\
\hline Freshmen & $13(17)$ \\
\hline Sophomore & $20(26)$ \\
\hline Junior & $10(13)$ \\
\hline Senior & $8(10)$ \\
\hline 5th year & \\
\hline Race/Ethnicity* & $39(56)$ \\
\hline White & $24(32)$ \\
\hline Black & $13(17)$ \\
\hline Other & $29(38)$ \\
\hline Residence & $47(62)$ \\
\hline On-campus & \\
\hline Off-campus & \\
\hline
\end{tabular}

*One athlete did not answer this question

\section{Nutritional Needs of the Athletes}

Eighty-nine percent of athletes consumed a meal 4 hours before a game, and 55 consumed a meal before a workout. Fewer athletes consumed snacks 30 minutes prior to games $(7.9 \%)$ or before a workout $(11.8 \%)$. There were no significant differences when comparing fueling practices before games and before workouts $(p=.2896)$. Those who did consume a pre-workout snack reported eating an energy bar or fruit. Most athletes $(80 \%)$ reported only consuming water during a workout. Only $20 \%$ reported consuming electrolyte replacement drinks such as Gatorade, or a protein shake during workouts. In addition, $75 \%$ reported lack of energy during a workout. Forty-eight (63.2\%) reported consuming a post-workout meal/snack within 30 minutes of a workout. Protein shakes were the most commonly reported recovery fuel $(38 \%)$. Fifty-three $(69.7 \%)$ reported taking some kind of dietary supplement, of those $53,37.7 \%$ reported consuming protein shakes/bars, and $24.5 \%$ reported using multivitamins. Less than $1 \%$ reported consuming creatine, fish oil, or joint supplements. 


\section{Athlete Attitudes Towards Additional Nutritional Services}

Most believed they would benefit from additional nutrition services (Figure 1). Though $93.4 \%$ believe they would benefit from a training table, only $42 \%$ were willing to have funds reallocated from their stipends to finance it.
There were no significant differences in the number of athletes willing to use their stipends for a training table versus those not willing based on grade ( $\mathrm{p}=0.957)$, position $(\mathrm{p}=0.54)$, or residence (on campus and off-campus) $(\mathrm{p}=0.982)$.

Figure 1. Athlete Attitudes Towards Additional Nutrition Services

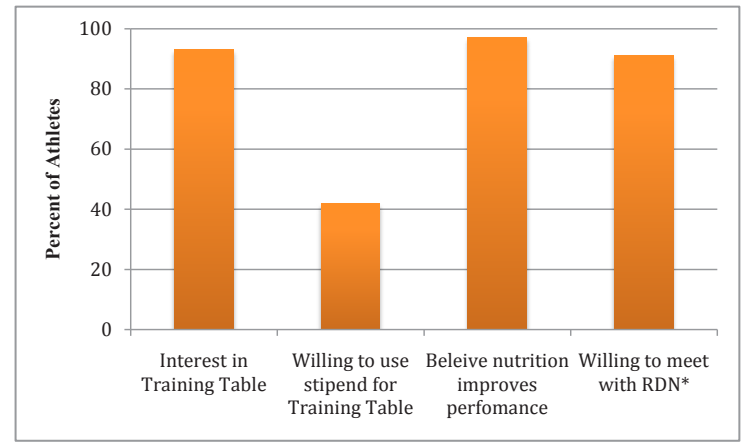

*Registered Dietitian Nutritionist

\section{Explanation of Attitudes Towards a Training Table}

Comments included in free-response questions indicated support of a training table: "nothing is available that close to a game."; "Training table would be greatly appreciated by our football team. We are at a huge disadvantage without.";"'Over the course of the season I have a hard time trying to maintain weight being away from my house for long periods of time. I am not able to eat enough food."; "I feel a training table can be of great benefit, especially after practice when I feel too tired to cook." Some athletes voiced concern about their stipends being insufficient to meet their needs and were not in favor of decreasing that to fund a training table. Some athletes made comments such as, "If the food is good I am more than happy to have my stipend pay for a training table. But if the food is garbage I won't eat it and it'll be a waste of money."

\section{Discussion}

Athletes' reported fueling patterns were likely insufficient to optimally fuel workouts and meet nutrient needs, as was demonstrated in previous research $[2,3]$. For example, Jonnalagadda, Rosenbloom, and Skinner reported that athletes ate an average of 3.6 times per day suggesting insufficient fueling [2]. Another indicated that collegiate football players consume diets that are inadequate to meet their estimated needs to maintain their high volume and intensity training loads [3].Though most athletes in the current study reported consuming a meal four hours before practice/games, few consumed a snack within the hour prior to exercise. In addition, most athletes in the current study only consumed water during their workouts. Consumption of a sports beverage or other source of fluid, carbohydrates, and electrolytes may improve hydration and fueling during exercise [1]. Three quarters of the participants reported feeling fatigue during practice. Undoubtedly high intensity of workouts contributes to fatigue, but proper fueling and hydration before and during exercise can decrease risk for fatigue [1]. Consuming a pre-workout snack may improve performance during workouts and contribute to their high caloric needs; however, athletes in the present study did not properly fuel pre and post workouts. More athletes in the current study (67\%) reported supplement use than was reported by athletes in the study conducted by Jonnalagadda Rosenbloom, and Skinner (42\%) [2].

Starting a training table at this division 1 school may improve athletes' dietary intake. Easy access to healthy foods such as a fueling station and/ or training table may increase the percentage of athletes who consume a snack prior to exercise, which may have positive impacts on body composition, anaerobic power, and endurance [4]. A training table provides the opportunity for point-of-decision signage, which has promoted increased awareness of healthy food options among college students $[13,14]$. The types and amount of food athletes eat may be influenced by time, peer influences, etc. [15]. Mealtime nutrition education by a RDN may help address these and other factors influencing athlete food choices.

Most athletes believed proper nutrition could improve their performance and were willing to meet with a RDN. Previous research indicates that athletes who met with a RDN reported improved nutrition knowledge and improved calorie and nutrient intake [10]. A RDN could provide nutrition education about nutritional needs, proper use of supplements including protein and creatine. Registered dietitian nutritionists can also educate athletes about strategies to ensure optimal frequency of eating, and can design specialized diets for athletes with allergies, intolerances, diseases, etc. Registered dietitian nutritionists are recognized as nutrition experts and are members of an ideal staff for student athletes [1]. Though ATs and SCSs may have some nutritional knowledge, designing diets is out of their scope of practice [9]. 
An interesting finding was that though most athletes were in favor of having a training table, fewer than half were willing to have money from their stipend reallocated to fund it. Athletes' comments suggest that they feel that their stipends are currently insufficient and highlight the need for the athletes to perceive that the training table food is of high quality and worth the cost.

\section{Limitations}

As this was a preliminary study to guide practices at one university, only one team was studied. Therefore, results may not be generalizable to other teams. The study was also limited by reliance on self-report data and lack of formal dietary assessment. This study had a high athlete response rate and data regarding nutrition needs from smaller institutions that do not employ a RDN is needed.

\section{Conclusion}

These findings suggest that the athletes' fueling and hydration practices were suboptimal. Most athletes believed they would benefit from meeting with a sports dietitian nutritionist and obtaining adequate fueling at a training table. Prior research has highlighted the importance of adequate fueling for athletic performance and the benefits of having a sports dietitian nutritionist on staff in a collegiate athletic department. Further research is needed to determine effectiveness of training tables as well as the feasibility and sustainability in funding to support a sports dietitian nutritionist and/or training table.

\section{References}

1. American Dietetic Association, Dietitians of Canada, American College of Sports Medicine, Rodriguez NR, Di Marco NM, et al. (2009) American College of Sports Medicine Position Stand. Nutrition and Athletic Performance. Med Sci Sports Exer 41: 709-731.

2. Jonnalagadda SS, Rosenbloom CA, Skinner R (2001) Dietary Practices, Attitudes, and Physiological Status of Collegiate Freshman Football Players. J Strength Cond Res 15: 507-513.

3. Cole CR, Salvaterra GF, Davis JE, Borja ME, Powell LM, et al. (2005) Evaluation of Dietary Practices of National Collegiate Athletic Association Division I Football Players. J Strength Cond Res 19: 490494.

4. Benardot D, Martin DE, Thompson WR, Roman S (2005) Between-Meal Intake Effects on Body Composition, Performance, and Total Caloric Consumption in Athletes. Med Sci Sport Exer 37: 339S.
5. Mathews EM, Wagner DR (2008) Prevalence of Overweight and Obesity in Collegiate American Football Players, by Position. J Am Coll Health 57: 33-38.

6. Wilkerson GB, Bullard JT, Bartal DW (2010) Identification of Cardiometabolic Risk Among Collegiate Football Players. J Athl Train 45: 67-74.

7. Buell JL, Calland D, Hanks F, Johnston B, Pester B, et al. (2008) Presence of Metabolic Syndrome in Football Linemen. J Athl Train 43: 608-616.

8. http://www.sportsrd.org/Full-time_Sports_RDs.html

9. Torres-McGehee TM, Pritchett KL, Zippel D, Minton DM, Cellamare A, et al. (2012) Sports Nutrition Knowledge among Collegiate Athletes, Coaches, Athletic Trainers, and Strength and Conditioning Specialists. J Athl Train 47: 205-211.

10. Valliant MW, Emplaincourt HP, Wenzel RK, Garner BH (2012) Nutrition Education by a Registered Dietitian Improves Dietary Intake and Nutrition Knowledge of a NCAA Female Volleyball Team. Nutrients 4: 506-516.

11. Hale, M, "Nutritional Habits \& Knowledge in the Division I Collegiate Football Player" (2013). All Graduate Plan B and other Reports. Paper 283.

12. http://grfx.cstv.com/photos/schools/fres/genrel/auto_pdf/2011-12/ misc_non_event/sport-nutrition-survey.pdf.

13. Peterson S, Duncan DP, Null DB, Roth SL, Gill L (2010) Positive Changes in Perceptions and Selections of Healthful Foods by College Students after a Short-Term Point-of-Selection Intervention at a Dining Hall. J Amer Coll Health 58: 425-431.

14. Reed JA, Powers A, Greenwood M, Smith W, Underwood R (2011) Using "Point of Decision" Messages to Intervene on College Students' Eating Behaviors. Am J Health Promot 25: 298-300.

15. Long D, Perry C, Unruh SA, Lewis N, Stanek-Krogstrand K (2011) Personal Food Systems of Male Collegiate Football Players: A Rounded Theory Investigation. J Athl Train 46: 688-695.

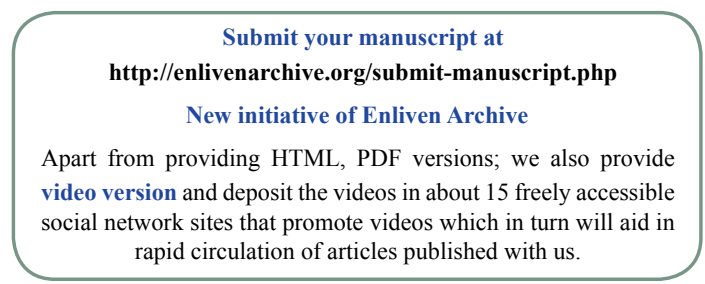

